\title{
A COMPARISON OF TRACHEAL INTUBATION USING THE AIRTRAQ AND THE MACINTOSH LARYNGOSCOPE- A PROSPECTIVE STUDY
}

\author{
Ravindra Gandhi', Asha Attar ${ }^{2}$
}

${ }^{1}$ Associate Professor, Department of Anaesthesiology, Vedantaa Institute of Medical Sciences, Sasvand, Maharashtra, India. ${ }^{2}$ Assistant Professor, Department of Anaesthesiology, Vedantaa Institute of Medical Sciences, Sasvand, Maharashtra, India.

\begin{abstract}
BACKGROUND
Airtraq optical laryngoscope is a novel tracheal intubation device. It can easily be used for both normal as well as complicated cases. In this study, Airtraq Laryngoscope was compared with Macintosh Laryngoscope when studying the performance of anaesthetists with difficult airway with respect to the haemodynamic parameters. The Airtraq is a new, single use, indirect laryngoscope that was developed in 2005. We wanted to compare the efficacy of conventional Macintosh laryngoscope with newly developed Airtraq laryngoscope with regard to various haemodynamic parameters and ease of intubation.
\end{abstract}

ABSTRACT

\section{METHODS}

This prospective comparative study was carried out in Vedantaa Institute of Medical Sciences, Palghar, on 80 adult ASA grade I \& II patients after written consent was obtained from the study participants and approval from the institutional ethical committee. These patients were randomly assigned into two groups. All patients were intubated by an anaesthetist experienced in the use of each method of laryngoscopy and consequences of haemodynamic parameters. Statistically analysis was performed using Microsoft Excel, SPSS software and p value of less than 0.05 was considered as statistically significant.

\section{RESULTS}

In this study, patients were randomly assigned into two groups. Participants were comparable with regard to demographics and haemodynamic parameters. The study revealed that there was a statistically significant increase in systolic blood pressure and diastolic blood pressure following intubation in both the groups.

\section{CONCLUSIONS}

Both Airtraq and Macintosh laryngoscopes are equally effective in tracheal intubation in normal airways. We found that there was a significant difference in ease of intubation and glottic view with both the devices. Airtraq had fewer side effects as compared Macintosh method.

\section{KEY WORDS}

Airtraq Laryngoscope, Macintosh Laryngoscope, ASA Grade I \& II, Haemodynamic Parameters

HOW TO CITE THIS ARTICLE: Gandhi R, Attar A. A comparison of tracheal intubation using the airtraq and the macintosh laryngoscope- a prospective study. J. Evolution Med. Dent. Sci. 2019;8(28):2283-2287, DOI: 10.14260/jemds/2019/500

\section{BACKGROUND}

Macintosh direct laryngoscopy is the most frequently used technique for endotracheal intubation in anaesthesia and intensive care. Intubating trachea and securing manage the difficult airway is a challenge for the anaesthetist. ${ }^{1}$ Laryngoscopes play an important role of general anaesthesia. The Airtraq optical Laryngoscope is an intubation device designed to difficult airway management of normal and emergency conditions. ${ }^{2}$ The anaesthesiologist required to consider strategies to except and manage patients with difficult airways. These perceiving the potential problems, different options, and selecting an appropriate plan for the single patient. $^{3}$ The Airtraq laryngoscope was a newly developed in 2005, to used tracheal intubation for both the normal and difficult airway.

'Financial or Other Competing Interest': None.

Submission 07-03-2019, Peer Review 25-06-2019,

Acceptance 05-07-2019, Published 15-07-2019.

Corresponding Author:

Dr. Asha Attar,

Sewa Nursing Home, Sarawali,

Damanu Road (E),

District Parghar-401602,

Maharashtra, India.

E-mail: asha.attar63@gmail.com

DOI: $10.14260 /$ jemds $/ 2019 / 500$
It is not surprising that newly designee intubation device that improves glottic visualisation and ease of use to tracheal intubation. The results of overstated curvature of the Airtraq blade and internal arrangement of optical components, it had been designed for visualisation the glottis without alignment of the oral, pharyngeal and tracheal axes. ${ }^{4,5}$ The consequences collateral laryngeal exposure may should less movement of the cervical spine as compared to Macintosh laryngoscopes. ${ }^{6}$ The blade of the Airtraq consists of two side by side channels, one side channels acts as a conduit through which a endotracheal tube (ETT) can be inserted and the other side channel uses a series of lenses, prisms, and mirrors create an image from the illuminated tip to a proximal viewfinder, giving a high-quality wide-angle view of the glottis and surrounding structures, and the tip of the tracheal tube. ${ }^{7}$ The Airtraq is anatomically shaped and size can be used with standard ETTs. To use the Airtraq device, blade must be inserted into mouth along with centre of the tounge, with the tip positioned in the left vallecula. Where necessary, the epiglottis can be lifted by elevating the blade into the vallecula. The ETT does not obstruct the endoscopic view of the vocal cords during tracheal intubation. ${ }^{8}$ The aim of this study was to compare the efficacy of conventional Macintosh laryngoscope with newly developed Airtraq laryngoscope various haemodynamic parameter and ease in intubation. 


\section{METHODS}

This prospective study was carried out in Vedantaa Institute of Medical Sciences, Palghar, surgical intensive care unit from the duration was July 2016 to June 2017 after approval of the institutional ethical committee. In this study was conducted in 80 adult intensive care patients with ASA grade I \& II and the age group between 20 to 65 years. The Patients were randomly assigned by each group by random number divided into two equal groups with 40 in each group and all of them underwent two laryngoscopies. In this study was conducted in the department of anaesthesia of Vedantaa institute of medical sciences, Palghar. 40 patients were intubated with the Airtraq laryngoscope to use the Airtraq device, the blade must be inserted into the mouth and 40 patients were intubated with the Macintosh laryngoscope. In this prospective comparative study was carried out after the institutional ethical committee approval and when informed consent was taken, we studies patients scheduled for any kind of surgery who required tracheal intubation.

\section{Inclusion Criteria}

1. Patient's age group between 20 to 65 years.

2. Patients need for emergency endotracheal intubation in intensive care unit.

\section{Exclusion Criteria}

1. Patients requesting regional anaesthesia.

2. Patients required endotracheal intubation due to severe oxygen desaturation $\left(\mathrm{SpO}_{2}<80 \%\right)$.

3. History of a difficult intubation.

In this study, 80 patients with ASA grade I and II who agreed to participate in the study and gave written informed consent were included. For each patient, age, sex, weight and ASA grade were collected. The ASA grade was examined by the anaesthesiologist who would perform the intubation at the time of during surgery. In the operation theatre after establishing an intravenous route, a ringer lactate solution was started. All patients received intravenous glycopyrrolate 0.2 $\mathrm{mg}$, ondansetron $0.1 \mathrm{mg} / \mathrm{kg}$. All patients received a standardised general anaesthesia. Standard monitoring, including electrocardiograph (ECG), non-invasive blood pressure (NIBP), oxygen saturation $\left(\mathrm{SaO}_{2}\right)$, end tidal carbon dioxide $\left(\mathrm{EtCO}_{2}\right)$, was continuously performed. Prior to induction of anaesthesia, all patients were given fentanyl (2 $\mu \mathrm{g} / \mathrm{kg}$ ) intravenously. A sleep dose of propofol (2-3 mg/kg) was titrated to induce anaesthesia. Following induction of anaesthesia, all patient's lungs manually ventilated with Isoflurane (1-2\%) in oxygen $100 \%$. Neuromuscular blocker was achieved using rocuronium $(0.9 \mathrm{mg} / \mathrm{kg}$ i.v.). trachea was intubated 90 seconds later. Thereafter, the lungs were mechanically ventilated for the duration of the procedure and anaesthesia was maintained using Isoflurane $(0.2-0.8 \%)$ in a mixture of nitrous oxide and oxygen in a 1: 1 ratio. No other medications were administered, or procedures performed, during the 5-min data collection period following tracheal intubation. In this study the outcome were record the total time of perform intubation and check the correct placement of endotracheal tube. Further management was Left to the discretion of the anaesthesiologist providing care for the patient.

\begin{tabular}{|c|c|c|c|}
\hline & Airtraq Group (AL) & Macintosh Group (ML) & \multirow{2}{*}{ p Value } \\
\cline { 1 - 3 } Variable Name & Mean \pm SD & Mean \pm SD & \\
\hline Age (Years) & $41.25 \pm 10.517$ & $40.85 \pm 11.093$ & 0.239 \\
\hline Weight (kg.) & $55.35 \pm 6.298$ & $57.25 \pm 7.625$ & 0.109 \\
\cline { 1 - 3 } & &
\end{tabular}

Table 1. Comparison of Demographic Data Between the Two Groups

\begin{tabular}{|c|c|c|c|c|}
\hline \multicolumn{2}{|c|}{} & $\begin{array}{c}\text { Airtraq Group } \\
\text { (AL) }\end{array}$ & $\begin{array}{c}\text { Macintosh Group } \\
\text { (ML) }\end{array}$ & p Value \\
\cline { 2 - 4 } \multicolumn{2}{|c|}{} & Frequency (\%) & Frequency (\%) & \\
\hline \multirow{2}{*}{ Sex } & Female & 21 & 15 & \multirow{2}{*}{0.178} \\
\cline { 2 - 4 } & Male & 19 & 25 & \multirow{2}{*}{1.000} \\
\hline \multirow{2}{*}{$\begin{array}{c}\text { ASA } \\
\text { Classification }\end{array}$} & 1 & 27 & 27 & 13 \\
\cline { 2 - 5 } Table 2. Comparison of Different Parameters Between the Groups \\
\cline { 2 - 4 }
\end{tabular}

\begin{tabular}{|c|c|c|c|c|}
\hline & & $\begin{array}{c}\text { Airtraq Group } \\
\text { (AL) }\end{array}$ & $\begin{array}{c}\text { Macintosh } \\
\text { Group }\end{array}$ & \\
\hline & & & (ML) & \multirow{2}{*}{ p Value } \\
\cline { 3 - 5 } & & Mean \pm SD & Mean \pm SD & \\
\hline \multirow{2}{*}{$\begin{array}{c}\text { Airway } \\
\text { management }\end{array}$} & Mouth opening & $4.225 \pm 0.3179$ & $4.230 \pm 0.3091$ & 0.945 \\
\cline { 2 - 5 } & Thyromental distance & $6.059 \pm 0.3211$ & $6.332 \pm 0.3153$ & 0.418 \\
\cline { 2 - 5 } & Inter-incisor distance & $4.030 \pm 0.3742$ & $4.326 \pm 0.3601$ & 0.632 \\
\hline
\end{tabular}

Table 3. Comparison of Airway Management Parameters Between the Two Groups

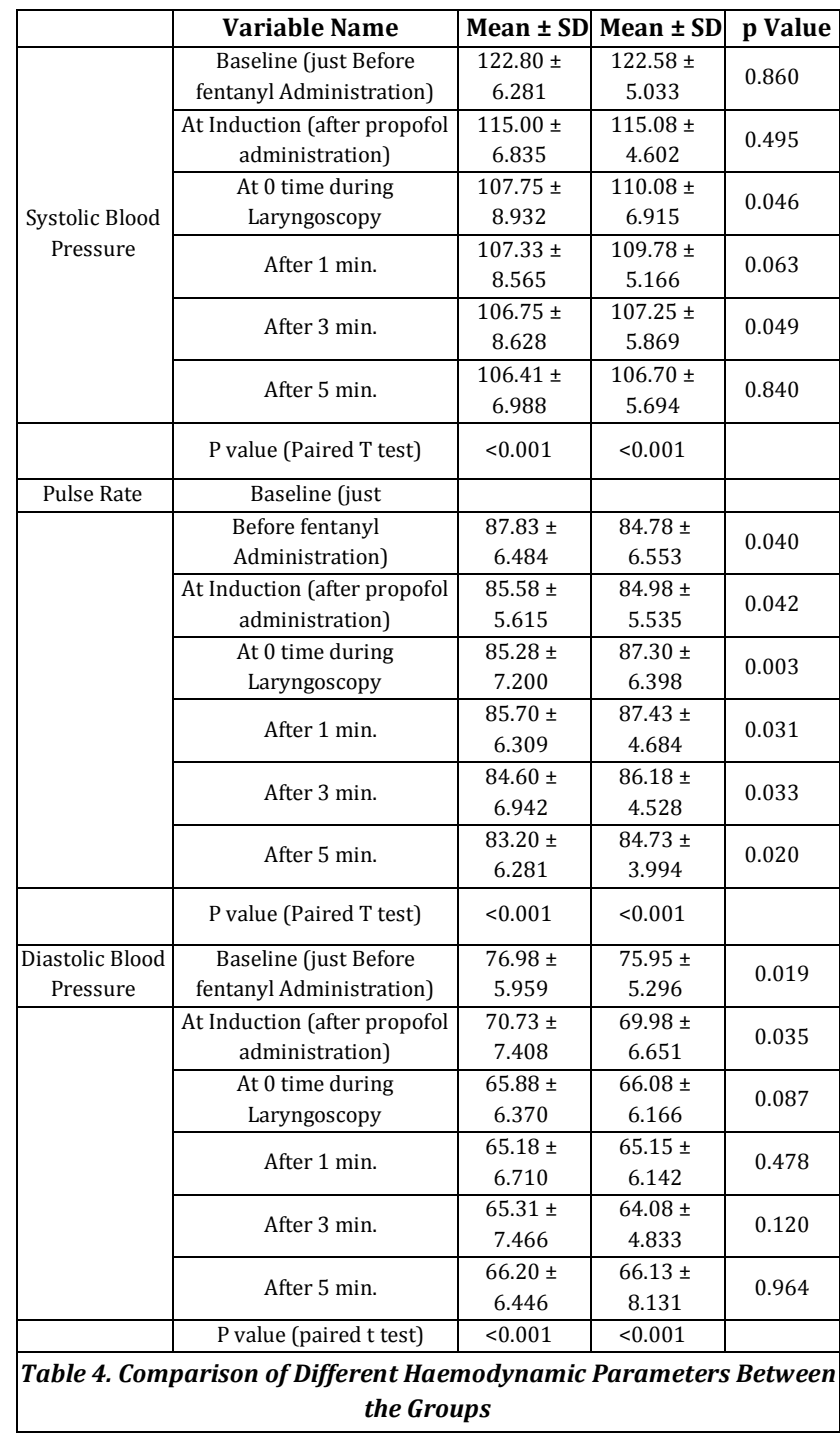

Haemodynamic measurements (Systolic, diastolic and mean arterial blood pressure) and oxygen saturation were recorded just before intubation and during the $0,1,3$ and 5 min after intubation. Data were analysed by using Microsoft office excel version 2007. Quantitative data was expressed as 
mean \pm SD and analysed using independent $t$ test between group and paired t test within group. Qualitative data was expressed as frequency and percentage and analysed using chi square test. $\mathrm{P}$ value less than 0.05 considered statistically significant.

\section{RESULTS}

Statistical data analysis was conducted using Microsoft Excel 13 and IBM SPSS 23. For the study design, 40 patients were intubated using Airtraq Laryngoscope and 40 patients were intubated using Macintosh Laryngoscope in random order. All analyses were performed on an intention to treat basis, haemodynamic parameters, patients' characteristics data and data for the total time of intubation. Difficult score was analysed using chi square test. The comparison of haemodynamic data was analysed using chi square test. Data are represented as a Mean (SD) or as a Median (Inter quartile Range) as appropriate, with categorical data represented as a numbers and frequency. The Alpha level of significance for all analysis was set as $P$ value is less than 0.05 .

In this study, a total of 80 participants were included. In Group Airtraq Laryngoscope, mean age of the participants was $41.25 \pm 10.517$ and Group Macintosh Laryngoscope, mean age were $40.85 \pm 11.093$. In Group Airtraq Laryngoscope, average weight of the participants was $55.35 \pm 6.298$ and Group Macintosh Laryngoscope, average weight of the participant were $57.25 \pm 7.625$. There is no statistically difference of Age and weight between the two studied groups. (Table 1). There were no statistically significant differences between the two studied groups as regards demographic data (Sex and ASA physical status) (Table 2). During the airway management all the variables like mouth opening, thyromental distance and inter-incisor distance was found to be not significant (Table 3). Haemodynamic changes were analysed in the present study; In Group Airtraq Laryngoscope, average systolic blood pressure at the baseline of the participants were $122.80 \pm$ 6.281 and Group Macintosh Laryngoscope, average systolic blood pressure at the baseline of the participant were 122.58 \pm 5.033 . There is no statistically difference of baseline in systolic blood pressure between the two studied groups. In Group Airtraq Laryngoscope, average systolic blood pressure at the induction of the participants were $115.00 \pm 6.835$ and Group Macintosh Laryngoscope, average systolic blood pressure at the induction of the participant were $115.08 \pm$ 4.602. There is no statistically difference of induction in systolic blood pressure between the two studied groups. In Group Airtraq Laryngoscope, average systolic blood pressure at the 0 time during laryngoscope of the participants were $107.75 \pm 8.932$ and Group Macintosh Laryngoscope, average systolic blood pressure at the 0 time during laryngoscope of the participant were $110.08 \pm 6.915$. There is statistically difference of the 0 time during laryngoscope in systolic blood pressure between the two studied groups. In Group Airtraq Laryngoscope, average systolic blood pressure after $1 \mathrm{~min}$ of the participants were $107.33 \pm 8.565$ and Group Macintosh Laryngoscope, average systolic blood pressure after $1 \mathrm{~min}$ of the participant were $109.78 \pm 5.166$. There is no statistically difference after $1 \mathrm{~min}$ in systolic blood pressure between the two studied groups. In Group Airtraq Laryngoscope, average systolic blood pressure after $3 \mathrm{~min}$ of the participants were $106.75 \pm 8.628$ and Group Macintosh Laryngoscope, average systolic blood pressure after $3 \mathrm{~min}$ of the participant were
$107.25 \pm 5.869$. There is statistically difference after $3 \mathrm{~min}$ in systolic blood pressure between the two studied groups. In Group Airtraq Laryngoscope, average systolic blood pressure after $5 \mathrm{~min}$ of the participants were $106.41 \pm 6.988$ and Group Macintosh Laryngoscope, average systolic blood pressure after $5 \mathrm{~min}$ of the participant were $106.70 \pm 5.694$. There is no statistically difference after $5 \mathrm{~min}$ in systolic blood pressure between the two studied groups.

In Group Airtraq Laryngoscope, average Pulse rate at the baseline of the participants were $87.83 \pm 6.484$ and Group Macintosh Laryngoscope, average Pulse rate at the baseline of the participant were $84.78 \pm 6.553$. There is statistically difference of baseline in Pulse rate between the two studied groups. In Group Airtraq Laryngoscope, average Pulse rate at the induction of the participants were 85.58 \pm 5.615 and Group Macintosh Laryngoscope, average Pulse rate at the induction of the participant were $84.98 \pm 5.535$. There is statistically difference of induction in pulse rate between the two studied groups. In Group Airtraq Laryngoscope, average Pulse rate at the 0 time during laryngoscope of the participants were 85.28 \pm 7.200 and Group Macintosh Laryngoscope, average Pulse rate at the 0 time during laryngoscope of the participant were $87.30 \pm 6.398$. There is statistically difference of the 0 time during laryngoscope in pulse rate between the two studied groups. In Group Airtraq Laryngoscope, average Pulse rate after 1 min of the participants were $85.70 \pm 6.309$ and Group Macintosh Laryngoscope, average Pulse rate after $1 \mathrm{~min}$ of the participant were $87.43 \pm 4.684$. There is statistically difference after $1 \mathrm{~min}$ in pulse rate between the two studied groups. In Group Airtraq Laryngoscope, average Pulse rate after 3 min of the participants were $84.60 \pm 6.942$ and Group Macintosh Laryngoscope, average Pulse rate after $3 \mathrm{~min}$ of the participant were $86.18 \pm 4.528$. There is statistically difference after $3 \mathrm{~min}$ in pulse rate between the two studied groups. In Group Airtraq Laryngoscope, average Pulse rate after $5 \mathrm{~min}$ of the participants were 83.20 \pm 6.281 and Group Macintosh Laryngoscope, average Pulse rate after $5 \mathrm{~min}$ of the participant were $84.73 \pm 3.994$. There is statistically difference after $5 \mathrm{~min}$ in pulse rate between the two studied groups.

In Group Airtraq Laryngoscope, average diastolic blood pressure at the baseline of the participants were 76.98 \pm 5.959 and Group Macintosh Laryngoscope, average diastolic blood pressure at the baseline of the participant were $75.95 \pm 5.296$. There is statistically difference of baseline in diastolic blood pressure between the two studied groups. In Group Airtraq Laryngoscope, average diastolic blood pressure at the induction of the participants were $70.73 \pm 7.408$ and Group Macintosh Laryngoscope, average diastolic blood pressure at the induction of the participant were $69.98 \pm 6.651$. There is statistically difference of induction in diastolic blood pressure between the two studied groups. In Group Airtraq Laryngoscope, average diastolic blood pressure at the 0 time during laryngoscope of the participants were $65.88 \pm 6.370$ and Group Macintosh Laryngoscope, average diastolic blood pressure at the 0 time during laryngoscope of the participant were $66.08 \pm 6.166$. There is statistically difference of the 0 time during laryngoscope in diastolic blood pressure between the two studied groups. In Group Airtraq Laryngoscope, average diastolic blood pressure after $1 \mathrm{~min}$ of the participants were $65.18 \pm 6.710$ and Group Macintosh Laryngoscope, average diastolic blood pressure after $1 \mathrm{~min}$ of the participant were $65.15 \pm 6.142$. There is no statistically difference after 1 
min in diastolic blood pressure between the two studied groups. In Group Airtraq Laryngoscope, average diastolic blood pressure after $3 \mathrm{~min}$ of the participants were $65.31 \pm$ 7.466 and Group Macintosh Laryngoscope, average diastolic blood pressure after $3 \mathrm{~min}$ of the participant were $64.08 \pm$ 4.833. There is no statistically difference after $3 \mathrm{~min}$ in diastolic blood pressure between the two studied groups. In Group Airtraq Laryngoscope, average diastolic blood pressure after 5 min of the participants were $66.20 \pm 6.446$ and Group Macintosh Laryngoscope, average diastolic blood pressure after $5 \mathrm{~min}$ of the participant were $66.13 \pm 8.131$. There is no statistically difference after $5 \mathrm{~min}$ in diastolic blood pressure between the two studied groups. There was a statistically significant increase in all variables at all periods following intubation in both the group (Table 4). Also, the percentage of oxygen saturation, there was no significant difference between the two groups. In postoperative period, 2 patients in Macintosh Laryngoscopy group experienced hoarseness of voice while 4 patients experience moderate throat pain and 20 patients experienced mild pain. In group Airtraq Laryngoscopy, 14 patients experienced mild throat pain and 3 patients experienced Moderate pain.

\section{DISCUSSION}

Airway management remains a vital primary skill for anaesthetist through history, many devices and instruments have been used to ease the burden of this crucial technique. Despite advances in medical technology, emergent orotracheal intubation continues to challenge even the most experienced anaesthetist. ${ }^{9}$ In the present study we compare the Macintosh Laryngoscopy (ML) with Airtraq Laryngoscopy (AL) to record the laryngoscopy \& intubation time, intubation changes in Pulse rate \& Blood Pressure, ASA grading, also show statistically significant changes during the intubation procedure at all periods following intubation when compared to the pre-induction values. ASA grading was assessed at the time of laryngoscopy, Group Airtraq had $33.75 \%$ of patients with ASA grade I and group Macintosh had $33.75 \%$ of patients with ASA grade I, Also $16.25 \%$ of patients in Airtraq group had ASA grade II compared to $16.25 \%$ of patients in Macintosh group, Hence ASA grade is similar performed in both the group. On comparing the airway management parameter with two groups; the Airtraq laryngoscopy resulted in significantly similar with Macintosh laryngoscopy. Laryngoscopy and intubation time were calculated from introduction to removal of laryngoscope blade from mouth and was taken in sec. Airtraq laryngoscopy and Macintosh laryngoscopy for laryngeal intubation were taken similar time in secs. Most of the patients were intubated in $0-5$ secs in both the groups. In our study found that intubation by anaesthesiologist is performed more similar the Airtraq Laryngoscope with Macintosh Laryngoscope using the values of Systolic, Diastolic blood pressure and Pulse rate. However, the difference of two studied groups is not statistically significant. On comparing the two groups together; the Airtraq Laryngoscopy mean time for laryngeal intubation is same as compared to the Macintosh Laryngoscopy mean time

and the difference is statistically not significant. Similar results were documented by Maharaj et al.10 when compared Airtraq Laryngoscopy with the Macintosh Laryngoscopy for intubating. Airtraq Laryngoscopy group showed less haemodynamic stimulation and pressor effects than the Macintosh Laryngoscopy group. These findings were the result of the absence of head/neck manipulations as well as the shorter duration of the intubation trials by the Airtraq Laryngoscopy. The same results were reported by Costello et al.11 this study showed that post intubation hoarseness of voice was nil in Airtraq Laryngoscopy group while this difficulty was found in Macintosh Laryngoscopy group. Along with this side effect post intubation throat pain was more in Macintosh Laryngoscopy group with severe degree.

\section{CONCLUSIONS}

The Airtraq laryngoscope is a novel single use tracheal intubation device. This is used for the management of both normal and difficult airway; it is fast, easy to use, gets an easy view of the larynx without moving the cervical spine or causing haemodynamic stimulation. Both Airtraq and Macintosh laryngoscopes are equally effective in tracheal intubation in normal airways. We found that there was a significant difference in ease of intubation and glottic view with use of both the devices. Airtraq had fewer side effects as compared Macintosh method.

\section{REFERENCES}

[1] Peterson GN, Domino KB, Caplan RA, et al. Management of the difficult airway: a closed claims analysis. Anesthesiology 2005;103(1):33-9.

[2] Caplan RA, Posner KL, Ward RJ, et al. Adverse respiratory events in anaesthesia: a closed claims analysis. Anesthesiology 1990;72(5):828-33.

[3] Connelly NR, Ghandour K, Robbins L, et al. Management of unexpected difficult airway at a teaching institution over a 7- year period. J Clin Anaesth 2006;18(3):198204.

[4] Maharaj CH, Costello JF, Higgins BD, et al. Retention of tracheal intubation skills by novice personnel: a comparison of the Airtraq and Macintosh laryngoscopes. Anaesthesia 2007;62(3):272-8.

[5] Dhonneur G, Ndoko S, Amathieu R, et al. Tracheal intubation using the Airtraq in morbid obese patient undergoing emergency cesarean delivery. Anesthesiology 2007;106(3):629-30.

[6] Marks RR, Hancock R, Charters P. An analysis of laryngoscope blade shape and design: new criteria for laryngoscope evaluation. Can J Anaesth 1993;40(3):262-70.

[7] Cook TM, Tuckey JP. A comparison between the Macintosh and the McCoy laryngoscope blades. Anaesthesia 1996;51(10):977-80.

[8] Tse JC, Rimm EB, Hussain A. Predicting difficult endotracheal intubation in surgical patients scheduled for general anaesthesia: a prospective blind study. Anesth Analg 1995;81(2):254-8.

[9] Chrisen H, Maharaj B, Elma B, et al. Endotracheal intubation in patients with cervical spine immobilization. Anesthesiology 2007;107:53-9.

[10] Maharaj CH, Higgins BD, Harte BH, et al. Evaluation of ease of intubation with the Airtraq or Macintosh laryngoscope by anaesthetists in easy and simulated 


\section{Jemds.com}

difficult laryngoscopy: a manikin study. Anaesthesia. 2006;61(5):469-77.

[11] Maharaj CH, Costello JF, Harte BH, et al. Evaluation of the Airtraq and Macintosh laryngoscopes in patients at
Original Research Article

increased risk for difficult tracheal intubation. Anaesthesia 2008;63(2):182-8. 